\title{
Effects of Rainfall on Human Leptospirosis in Thailand: Evidence of Multi-Province Study Using Distributed Lag Non-linear Model
}

Arthit Phosri ( $\sim$ arthit.pho@mahidol.ac.th )

Mahidol University https://orcid.org/0000-0002-5541-867X

\section{Research Article}

Keywords: Human leptospirosis, Rainfall, Distributed lag non-linear model, Thailand

Posted Date: January 18th, 2022

DOI: https://doi.org/10.21203/rs.3.rs-1260888/v1

License: (c) (i) This work is licensed under a Creative Commons Attribution 4.0 International License.

Read Full License 


\section{Abstract}

Leptospirosis is a zoonotic bacterial disease that remains an important public health problem, especially in tropical developing countries. Some previous studies have revealed the outbreak of leptospirosis after heavy rain, but research determining its quantitative risks associated with rainfall in Thailand, especially at the national level, remains limited. The association between rainfall and leptospirosis was examined across 60 provinces of Thailand, and the heterogeneity of the estimated effects among provinces was also assessed. Monthly number of leptospirosis surveillance and meteorological data from 2007 to 2017 were obtained from the Bureau of Epidemiology and Thai Meteorological Department, respectively. A quasi-Poisson regression framework combined with the distributed lag non-linear model was used to estimate province-specific association between rainfall and human leptospirosis, adjusting for potential confounders. Province-specific estimates were then pooled to derive regional and national estimates using random-effect meta-analysis. The results found that the highest estimated risk of leptospirosis associated with rainfall was observed at the same month ( $\operatorname{lag} 0$ ). Using $0 \mathrm{~cm} /$ month of rainfall as a reference, the relative risks of leptospirosis associated with heavy (90th percentile), very heavy (95th percentile), and extremely heavy (99th percentile) rainfall at the national level were $1.0994(95 \% \mathrm{Cl}$ : $0.9747,1.2401), 1.1428$ (95\% Cl: $1.0154,1.2862)$, and 1.1848 (95\% Cl: $1.0494,1.3378)$, respectively. The heterogeneity of the estimates was found among provinces ( $12=27.1 \%, p$-value $<0.01$ ), where northern and north-eastern regions were identified as the highest risk of leptospirosis associated with rainfall. In particular, relative risks of leptospirosis associated with extremely heavy rainfall in northern and northeastern regions were 1.2362 (95\% Cl: $0.9110,1.6775)$ and 1.2046 (95\% Cl: $0.9728,1.4918)$, respectively. Increasing rainfall was associated with increased risks of leptospirosis, especially in the northern and northeastern regions of Thailand. This finding could be used for precautionary warnings against heavy rainfall.

\section{Introduction}

Leptospirosis is a globally significant zoonotic disease caused by the infection with pathogenic spirochete bacteria of the genusLeptospira(Levett 2001). It is endemic in many tropical regions and causes an outbreak after heavy rainfall and flooding (Haake and Levett 2015). The disease can be transmitted either via direct contact with infected urine of rodents or other wild and domestic mammals or throughexposure to contaminated environment, particularly water and soil(Bharti et al. 2003).Globalmorbidity due to leptospirosis is approximatelyone million withabout 60,000 deathsoccurring yearly, where the highest estimateswerefound in the GBD regions of South and Southeast Asia(Costa et al. 2015).Humansinfected with pathogenic Leptospiracould present a wide range of symptoms ranging from symptomless or subclinical manifestations of a febrile illness to severe infection, including jaundice, renal failure, pulmonary hemorrhage, and even death(Bharti et al. 2003; Levett 2001). Due to abroad spectrum of clinical manifestations of human infection, the incidence rate of human leptospirosis around the world is probably underreported, particularly in the areas with relatively inaccessible and limited diagnostic facilities(Bharti et al. 2003). 
Some favorable environmental conditions(e.g., wet and humid climates)couldinfluence the transmission of leptospirosis by modifying the biology of pathogens, and affecting the behaviors of their hosts. For example, pathogenssomewhat survive for longer period of time that might be several days or even months(Ridzlan et al. 2010), and population of pathogen hostsis likely to increase at the same time as the environmental condition is appropriate to reproduce(Perez et al. 2011). Agricultural workers are considered the most infected group because their intensive farming activities coincide with rainy season, where pathogenic leptospires in renal tubules of infected animalscan be shed in urine and contaminated in water environment. Some related studies have indicated thatrainfall might serve as an important driverfor human leptospirosis transmission(Lau et al. 2010; Mwachui et al. 2015; Pappas et al. 2008; Victoriano et al. 2009), and the association of rainfall with human leptospirosis has been indicated elsewhere, such as in Brazil (Hacker et al. 2020), China (Dhewantara et al. 2019), the Philippines (Matsushita et al. 2018), Sri Lanka (Robertson et al. 2012) andlndia (Premdas et al. 2019). In Thailand, human leptospirosis is endemic and becomes epidemic following heavy rainfall and flooding events(Altheimer et al. 2020; Chadsuthi et al. 2017; Gonwong et al. 2017). Many recent epidemiological studies in Thailand have investigated the association between meteorological factors (e.g., temperature, rainfall, and flooding) and incidence of human leptospirosis. However, the existing evidence did not consider non-linear associations, where the quantitative effects of different levels of rainfallon leptospirosis were not taken into account(Chadsuthi et al. 2012; Suwanpakdee et al. 2015). Moreover, the comprehensive study on the association between rainfall and leptospirosis covering multiple provinces with a range of geographical areas and climatic diversity has not been reported so far, where heterogeneity of the effect estimates in different regions might be observed.Therefore, the heterogeneityof the association between rainfall and human leptospirosis needs to be explored among different provinces and regions using an integrated national level investigation, so that findings can be used to support local,regional and national interventions accordingly.

In the current study, the effects of rainfall on human leptospirosis were estimated in 60 Thai provinces using distributed lag non-linear model (DLNM), allowing for simultaneous consideration of the delayed effect and non-linear exposure-response relationshipbetween rainfall and leptospirosis. The heterogeneity of the effect estimates in different provinces, as well as potential factors that are likely to explainthe heterogeneity were also examined throughthe random-effect multivariate meta-analysis using the maximum likelihood estimation approach to derive region-specific and poolednational estimates of the short-term effects of rainfall on leptospirosis.

\section{Materials And Methods}

Thailand has 76 provinces and 1 metropolitan, and can be classified in 5 regions according to the Tourism Authority of Thailand (Fig.1A). Climate condition of the country isusually influenced by tropical monsoon wind leading to have different seasons (i.e., summer, winter, and rainy season). In this study, 17 provinces were excluded because meteorological data (either rainfall or temperature or humidity) were unavailable in 11 provinces, andthe total number of human leptospirosis in another 6 provinces was reported less than $3 \%$ of total human leptospirosis casesthroughout the study period (i.e., $2007-2017$ ). 
Overall, 59 provinces and 1 metropolitan in 5 regions (i.e., north, northeast, central, east and south) were adopted in this study (Fig. S1).

\subsection{Meteorological data}

Daily data on meteorological variables, including rainfall, temperature and relative humidity, of each provincefrom January 2007 through December 2017 were obtained from weather monitoring stations operated by the Thai Meteorological Department. Monthly cumulative rainfall $(\mathrm{cm})$ was used in this study by accumulating daily cumulative rainfall within the same month of the same year in each province, whereas monthly average temperature and relative humidity in each province were applied by averaging daily average temperature and relative humidity for that particular month in that year. In the case of many weather monitoring stations situated in the same province, the average levels of each variable from those stations were then used as monthly exposure levels in that province. The average of monthly cumulative rainfall in each province throughout the study period is indicated in Fig. 1B.

\subsection{Human leptospirosis data}

Monthly dataon human leptospirosis in each province were obtained from the 506 surveillance database made bythe Bureau of Epidemiology under the Ministry of Public Health of Thailand during the periodsspanning fromJanuary 2007 toDecember 2017.The 506 surveillance systems has been undergone by collaborating with all public primaryhealth care units, secondary and tertiary hospitals, as well as some private hospitals in which the objective of this system was mainly for disease control and prevention. Data included monthly cumulative number of human leptospirosis in each month and province during the study period in which both clinical and laboratory conformed cases were included. For those with a diagnosis by laboratorytest, any positive results from either screening or confirmatory test must be detected. The screening methods can be performed usinglatex agglutination test, dipstick test, lateral flow test, or microcapsule agglutination test (MCAT), whereas confirmatory approaches can be tested using the immunofluorescent antibody test (IFA), microscopic agglutination test (MAT), enzymelinked immunosorbent assay (ELISA) for leptospirosis, culture, or polymerase chain reaction(Bureau of Epidemiology 2019). The spatial distribution of the total number of leptospirosis in each province of Thailand during the study period is shown in Fig. 1C.

\subsection{Meta-predictor data}

Province-specific data on population numbers and proportions of those populations with high educational level (i.e., completed bachelor and above) were obtained from the latest report (in 2010) of theNational Population and Housing Census conducted by the National Statistical Office (NSO) of Thailand (http://www.nso.go.th/sites/2014/Pages/home.aspx). The population and housing census is generally conducted every 10 years, where the latest version was made in 2010 . Moreover, provincespecific proportions of population working as agricultural workers were obtained from the Department of Agriculture Extension (http://www.agriinfo.doae.go.th/). These aforementioned data were used as meta- 
predictors in the multivariate meta-regression model to explain whether the difference among provincespecific estimates is likely to beexplainedby those possible predictors.

\subsection{Statistical analysis}

The data analytic approach in this study involved three steps including (1) estimating province-specific effects of rainfall on leptospirosis, (2) quantifying regional and national estimates, and (3) predicting the effects of rainfall on leptospirosis in each scenario of meta-predictors (i.e., diurnal temperature range (DTR), latitude, population number, proportion of population with higher education and with agricultural workers).

\subsubsection{Estimating province-specific effects of rainfall on leptospirosis}

A generalized linear modeling (GLM) frameworkwith quasi-Poisson regression combined with a distributed lag non-linear model (DLNM) was used to quantify the province-specific estimates of rainfall on leptospirosis by adjustingfor many potential confounders, including temperature, relative humidity, as well as seasonal variation and long-term trend(Gasparrini et al. 2010).To this model, the natural cubic spline function with three degrees of freedom (DF) for rainfall was applied in this study by placing spline knots at equally spaced values for rainfall range. Furthermore, a natural cubic spline function with 3 DF for temperature and humidity at moving average lag 0-3 months was used to control for temperature and relative humidity concerning the association between rainfall and leptospirosis. Month and year were also incorporated in the model as indicator variables to control for seasonal variation and long-term trend. The model used in this study is described below:

$\log \left[\mathrm{E}\left(\mathrm{Y}_{t}\right)\right]=\mathrm{a}+\beta\left(\operatorname{Rain}_{t, 1}\right)+n s\left(\operatorname{Temp}_{0-3,}, 3\right)+n s\left(\mathrm{RH}_{0-3,}, 3\right)+$ factor $\left._{\left(\text {Month }_{t}\right)}\right)+$ factor $\left._{\left(\text {Year }_{t}\right)}\right)$

where $Y_{t}$ denotes monthly cumulative number of leptospirosis at month $t . \beta$ is the coefficient of crossbasis matrix of monthly cumulative rainfall at month $t$ and lag lobtainedthroughfitting DLNM. Moreover, $n s\left(\mathrm{Temp}_{0-3}, 3\right)$ and $n s\left(\mathrm{RH}_{0-3}, 3\right)$ indicate the natural cubic splines for temperature and relative humidity at cumulative lag 0-3 months using 3 DF, respectively. For the terms factor(Month ${ }_{t}$ ) and factor(Year $\left.r_{t}\right)$ define an indicator variable for month and year at month $t$, respectively.

\subsubsection{Quantifying regional and national estimate}

The province-specific estimate of rainfall on leptospirosis at each lag structure was pooled using the maximum likelihood estimation approach. In particular, a multivariate random-effect meta-analysis was conducted to derive regional and national estimates of rainfall on leptospirosis(Gasparrini et al. 2012). The multivariate Cochran $Q$ test and $R^{2}$ statistics were used to measure residual heterogeneity. Furthermore, the best linear unbiased prediction (BLUP) was applied to derive the shrinkage version of the province-specific estimate of rainfall on leptospirosis because BLUP is able to estimate the missing of province-specific parameters obtained from the section2.4.1 by exploiting the information from other province-specific parameters included in meta-analysis through the between-study covariance 
matrix.Specifically, this approach allows province that has lower number of human leptospirosis cases or shorter time-series, larger uncertainty estimate, to borrow the information from other provinces that have larger number of human leptospirosis included in the meta-regression model(Gasparrini et al. 2012).

Based on the BLUP estimates, the relative risk (RR) of leptospirosis associated with exposure to rainfall at each lag structure was then determined by using $0 \mathrm{~cm} /$ month of rainfall as a reference point. Specifically, the RRs of leptospirosis associated with heavy (90th percentile), very heavy (95th percentile), and extremely heavy (99th percentile) rainfall relative toreference value inthe provincial level obtained through the BLUP method, as well as in the regional and national level were reported.

\subsubsection{Predicting effects of rainfall on leptospirosis in different scenarios of meta-predictors}

Each meta-predictor was added into the meta-regression model obtained from the section 2.4.2one at a time to examine its contribution to heterogeneity. The Wald test was used to measure the significance of meta-predictors and the differences between models. The Akaike Information Criterion (AIC) was also used to measure the goodness of model fit after incorporating each meta-predictor into the metaregression model, where the model that had the lowest AIC value was preferable. Moreover, the estimated effects of rainfall on leptospirosis were predicted under specific scenarios of each meta-predictor to quantify whether the amount of heterogeneity is explained by province-specific characteristics.

Specifically, the effect of rainfall on leptospirosis was estimated under 1st and 3rd quartiles of each meta-predictor. The exposure-response relationship between rainfall and leptospirosis for each specific scenarios of mate-predictor was also indicated.

The sensitivity analysis of the pooled estimates found at the national level was performed by changing DF for temperature and relative humidity that used to control for the possible meteorological confounders on rainfall-leptospirosis association. Moreover, maximum likelihood estimation(ML) in place of restricted maximum likelihood estimation (REML) was performed for multivariate meta-analysis. R Project for Statistical Computing Version 3.6.3 was applied for all analyses in this study (R Development Core Team 2019), using "dlnm" and "mvmeta" packages (Gasparrini 2011; Gasparrini et al. 2012).

\section{Results}

Summary statistics for monthly cumulative rainfall, monthly number of human leptospirosis cases, and other related meteorological variables in 60 provincesduring the period spanning from 2007 to 2017 are reported in Table 1. A total of 38,158 human leptospirosis cases werefound in 60 provinces during the study period. The average number of monthly leptospirosis cases was 4.9 ( 0 - 264) where the highest number of human leptospirosis was found in the north-eastern region with an average of $11.1(0-264)$ cases per month (Table S1). The mean of monthly cumulative rainfall during the study period was 15.3 (0.0 - 186.3) cmin which a broad range of rainfall distribution was observed among regions. Specifically, the highest rainfall was observed in the southern region with $22.4(0-148.8) \mathrm{cm}$ per month, whereas the lowest rainfall was found in the central region with $11.1(0.0-50.0) \mathrm{cm}$ per month throughout the study period (Table S1). Monthly average temperature and relative humidity during the study period were 
27.3(17.7 - 34.4) ${ }^{\circ} \mathrm{C}$ and 76.5 (43.4 - 92.2) \%, respectively. The summary statistics for province-specific parameters are shown in Table S2. The seasonal trend of rainfall was observed with higher rainfall occurring during rainy season (July - October) in all regions other than that in the southern regions, where higher rainfall was observed throughout the year (Fig. S2). There was no clear seasonal pattern of human leptospirosis other than that in the north-eastern region where higher number of human leptospirosis was observed during rainy season (July - October) (Fig. S3).

Summary statistics for province-specific characteristics (i.e., latitude, DTR, population number, proportion of population with higher education and with agricultural workers) are illustrated in Table 2 . These variables were used to assess whether the amount of residual heterogeneity is explained through the multivariate meta-regression model. The number of population was the highest in the central region with $13.52 \times 10^{5}$ people $\left( \pm 17.67 \times 10^{5}\right)$ and the central region also had higher proportion of population with higher education, whereas the lowest proportion of population with higher educational level was found in the north-eastern region with $6.75 \%( \pm 2.13)$ of the whole population residing within the region.In addition, the highest proportion of population working as agricultural workers wasfound in the north-eastern region at $12.87 \%$ ( \pm 2.01$)$, whereas the lowest proportion of population working as agricultural workers was observed in the central region at $6.78 \%( \pm 3.27)$ of the whole population residing within the region. These characteristicsfor each province are depicted in Table S3, and descriptive statistics (i.e., mean, minimum, 25th percentile, median, 75th percentile, and maximum) ofthese variables for all 60 provinces are shown in Table S4.

\subsection{Province-specific effects of rainfall on leptospirosis}

Province-specific effect of rainfall on leptospirosis, estimated using the BLUP approach, at lag 0 month is indicated in Fig. 2. The effects of rainfall on human leptospirosis were estimated at the 90th percentile (heavy rain), 95th percentile (very heavy rain), and 99th percentile (extremely heavy rain) of monthly cumulative rainfall for each provincerelative to $0 \mathrm{~cm} /$ month, which is expressed as RR and its $95 \%$ confidence interval $(\mathrm{Cl})$. The pooled RR of leptospirosis associated with rainfall at the 90th percentile $(34.5 \mathrm{~cm})$, 95th percentile $(41.6 \mathrm{~cm})$, and 99th percentile $(54.5 \mathrm{~cm})$ relative to $0 \mathrm{~cm}$ was 1.0994 (95\% Cl: $0.9747,1.2401), 1.1428$ (95\% Cl: $1.0154,1.2862)$, and 1.1848 (95\% Cl: 1.0494, 1.3378), respectively. The numerical province-specific RR, andthat of RR estimated through the BLUP approachat the same month (lag 0) areshown in Table S5.

\subsection{Quantifying region-specific and national estimates}

The multivariate random-effect meta-analysis was applied to pool province-specific RR as region-specific and national RR. Fig. 3 indicates therainfall-leptospirosis associations for theregion-specific and national level at different lag structures. The results suggested that the association between rainfall and human leptospirosis in Thailand, at the national level, was non-linear with significant heterogeneity. The estimated effect of rainfall on leptospirosis was the highest at lag 0 month and attenuating toward the null at later lags within 1 and 2 months, respectively. Specifically, the RR of leptospirosis associated with 
rainfall at the 99th percentile $(54.5 \mathrm{~cm})$ relative to $0 \mathrm{~cm}$ for national level was 1.1848 (95\% $\mathrm{Cl}$ : 1.0494, 1.3378), 0.9750 (95\% Cl: $0.8536,1.1136)$ and 0.9546 (95\% Cl: 0.8345, 1.0919) at lag 0, lag 1, and lag 2 months, respectively. The $R^{2}$ statistics and $p$-value from the Cochran Qtest for the association between rainfall and leptospirosis at lag 0 month were $27.1 \%$ and0.0007, respectively. Similar findings werealso observed at the region-specific level, but significant heterogeneity was not observed in the northern, north-

eastern, and southern region with $P^{2}$ of $7.6,14.2$, and $1.0 \%$, as well as $p$-value (Qtest) of $0.3348,0.2007$, and 0.5776 at lag 0 monthfor the northern, north-eastern, and southern regions, respectively. The numerical region-specific and national RR at different lag structures are reported in Table S6, and its corresponding $\mathcal{R}^{2}$ statistics and Cochran $Q$ testare presented in Table S7.

Fig.4 indicates the rainfall-leptospirosis association at lag 0 month classified by region. In general, increasing monthly cumulative rainfall was significantly associated with increasing risk of leptospirosis at the national level with significant heterogeneity among province-specific $\operatorname{RR}\left(R^{2}, 27.1 \%\right.$ and $p$-value $(Q$ test), 0.0007). This patternof the association was similar to that in the north-eastern and southern regions though it is not statistically significant and the heterogeneity of the province-specific RR within the region was not statistically significant (i.e., $R^{2}$ of $14.2 \%$ and $p$-value ( $Q$ test) of 0.2007 for the north-eastern and $R^{2}$ of $1.0 \%$ and $p$-value ( $Q$ test) of 0.5776 for the southern region). The rainfall-leptospirosis relationship in the northern region was non-linear and the heterogeneity of province-specific RR within the region was not significant ( $R^{2}$ of $7.6 \%$ and $p$-value ( $Q$ test) of 0.3348$)$. The RR of leptospirosis in the northern region sharply increased beginning after exposure to $30 \mathrm{~cm} / \mathrm{month}$ of monthly cumulative rainfall. However, the pattern of association in the central and eastern regions was unclear with larger uncertainty, especially in the eastern region, where the association lines of pooled RR were laidover the province-specific RR. The pooled estimate between monthly cumulative rainfall and human leptospirosis in the central and eastern regions showed significant heterogeneity with $R^{2}$ of $53.6 \%$ and $p$-value ( $Q$ test) of 0.0016 for the central and $R$ of $43.1 \%$ and $p$-value ( $Q$ test) of 0.0241 for the eastern region.

\subsection{Predicting effects of rainfall on leptospirosis in different scenarios of meta-predictors}

The large heterogeneity between province-specific associations of rainfall with leptospirosis was observed as displayed in Fig. 4 and Table S7. This heterogeneity mightbe explainedby the difference of the province-specific geographical and population characteristics (i.e., DTR, latitude, number of population, proportion of population with higher education and with registered agricultural workers). Thus, the aforementioned variables were included as meta-predictors in the multivariate meta-regression model. TheWald test was used to measure the significance of meta-predictors and the AIC was used to measure the goodness of model fit after incorporating each meta-predictor in the meta-regression model. The results show that DTR and latitude seemed to explain the heterogeneity, to some extent, among province-specific estimates with $R^{2}$ reduces from $27.12 \%$ in the model without meta-predictor to $27.02 \%$ and $26.52 \%$ in the model with DTR and latitude, respectively. Nevertheless, the residual heterogeneity remained significant ( $p$-value from Qtest <0.01). Furthermore, all meta-predictors included in this study did 
not contribute significantly to the model ( $p$-value from the Wald test $>0.05$ )and the model with intercept only, without meta-predictor, suggested the best model fit (the lowest AIC value) (Table S8).

Fig. 5 indicates the rainfall-leptospirosis association (lag 0 month) classified by each region at alternative scenarios (i.e., 25th and 75th percentiles) of geographical and population characteristics. The findings suggested that increasing province-specific DTR, latitude, and proportion of population with registeredagricultural workers from the 25th to 75th percentile would exacerbate the association between rainfall and human leptospirosis during heavy(90th percentile) and very heavy (95th percentiles) rainfall, whereas increasing of population number and proportion of population with higher education would suppress the association. Nevertheless, during extremely heavy(99th percentile) rainfall, the RR of leptospirosis increased when all aforementioned geographical and population characteristics were changed from the 25th to 75th percentile. The numerical RR of leptospirosis at 90th, 95th, and 99th percentiles of monthly cumulative rainfall relative to $0 \mathrm{~cm}$ for different scenarios of geographical and population characteristics is shown in Table S9.

\subsection{Sensitivity analysis}

The sensitivity analysis was performed to examine the robustness of the effect estimate. In this study, alternative DFs for temperature and humidity, as well as changing the method for multivariate metaregression model by using ML instead of REML were performed. The findings suggested that the pattern of the relationship between rainfall and leptospirosis was similar even when changing the DFs for temperature and humidity to control for possible meteorological confounders (Fig. S4). In addition, the shape of the relationship was robust after changing the method for the multivariate meta-regression model from REML to ML (Fig. S5). The model performance for some provinces is shown in Figs. S6, S7, S8, S9, and S10.

\section{Discussion}

This study investigated the relationship between rainfall and human leptospirosis in Thailand. Findings suggested that higher level of monthly cumulative rainfall was associated with increasing risk of leptospirosis, although the association varied significantly by provinces and regions. In particular, the association between rainfall and human leptospirosis seemed to be linear in the north-eastern and southern regions, whereas that in the northern region was non-linear where the RR of leptospirosissharply increased after exposure to $30 \mathrm{~cm} /$ month of monthly cumulative rainfall.However, the pattern of association in the central and eastern regions was unclear with larger uncertainty. This broad variation could be explained by the difference of province-specific geographical and population characteristics despite not being significant. Specifically, increasing province-specific DTR, latitude, and proportion of population with registered agricultural workers would exacerbate theassociation between rainfall and leptospirosis, whereas increasing population number and proportion of population withhigher education would suppress the association during heavy (90th percentile) and very heavy (95th percentile) rainfall. However, during extremely heavy (99th percentile) rainfall, increasing all aforementioned variables would 
exacerbate the association between rainfall and leptospirosis. This study is the first study in Thailand, to my knowledge, showing the nationally quantitative non-linear effects of rainfall on human leptospirosis. The results could be applicable to improve and develop the national preventive measures to reduce possible risk factors of human leptospirosis caused by climate change in Thailand.

Many previous epidemiological studies have revealed the significant association between rainfall and human leptospirosis, but the time lag reported from each study was differed. Specifically, a study conducted in the Reunion Island (Indian Ocean)showed that human leptospirosis was affected by monthly cumulative rainfall with previous 2 months(Desvars et al. 2011), whereas that in Ratnagiri and Thrissur citiesof India(Pawar et al. 2018; Premdas et al. 2019)as well as in Guadeloupe of the French overseas region(Herrmann-Storck et al. 2005)was affected with the previous 1 month. In addition, a study in Trinidad and Tobago revealed that the number of human leptospirosis was peaked at a lag of 1 to 2 months after the onset of heavy rainfall (Mohan et al. 2009), whereas a study in Thailand suggested thata lag of 8 to 10 months of rainfall yield the best model to predict the number of human leptospirosis in the northern and north-eastern regions (Chadsuthi et al. 2017). Those finding were inconsistent with the results found in this study, where the highest estimated effect of rainfall on human leptospirosis was observed at lag 0 month (same month) and attenuated at lag 1 and lag 2 months, respectively, at the national level. This finding was in agreement with previous study in the Philippines showing the risk of leptospirosis peaked at a lag of 2 weeks (Matsushita et al. 2018). These different time-lag patterns on the association between rainfall and human leptospirosis might be depending upon theunderlying geographical and demographical characteristics of the study location as well as method used to investigate the association, which require further investigation. However, the same month lag that was found in this study coincided with the fact that the pathogenic Leptospira can survive in the contaminated water and soil for approximately 2 weeks after shedding infected urine from infected rodents or other mammals (Levett 2001). This was also consistent with the average incubation period of leptospirosis, which is spanning from 7 to 12 days (ranging from 3 to 30 days) (Haake and Levett 2015).

The heterogeneity of the association between monthly total rainfall and human leptospirosis among provinces was observed and hypothesizing that this heterogeneity might be explained by provincespecific geographical and demographical characteristics that incorporated as meta-predictors in the multivariate meta-regression model. However, all specified meta-predictors included in this study (i.e., DTR, latitude, population number, proportion of population with higher education and proportion of population with registered agricultural workers) did not contribute significantly to the model and the model with intercept only, without meta-predictor, suggested the best model fit. Although, those specified meta-predictors did not contribute significantly to the meta-regression model, they still indicate, to some extent, that different levels of each meta-predictor could influence the association between rainfall and human leptospirosis (Fig. 5).For example, the association between rainfall and human leptospirosis significantly varied by province and region, where the estimated effects were evident in the northern, north-eastern, and southern regions, in spite of not being statistically significant. This finding might be explained by the proportions of population who have registered as agricultural workers in each region, where locations that havehigher proportion of registered agriculture workers could exacerbate the 
association between rainfall and leptospirosis. Specifically, the proportion of people working as agricultural workers accounted for $11.7,12.9$, and $11.2 \%$ in the northern, north-eastern, and southern regions, respectively. These groups of people might be inevitably exposed to the pathogenic Leptospira contaminated in water and soil, where they are in closely contact(Levett 2001; Matsushita et al. 2018; Mwachui et al. 2015; Suwanpakdee et al. 2015). This speculation canbe supported by the fact that increasing rainfall is likely to facilitate the survival of bacterial pathogenic Leptospirato survive fora longer period of time that could be potentially infected by rodents or other mammals. This situation might lead to an increase in the number of infected hosts (i.e., rodents and mammals)and consequently increase the possibility of exposure to the pathogenic Leptospira, excreted in urine from infected hosts, among farmers working in wet and muddy areas(Tangkanakul et al. 2000; Watt et al. 2003).

The educational level was also shown to describe the association between rainfall and human leptospirosis, where the locations that had lower proportion of population with higher educational level were likely to increase the potential of rainfall to exacerbate the onset of human leptospirosis. This was in agreement with the results from this study showing the effect of rainfall on leptospirosis was prominent in the north-eastern, northern, and southern regions, where the proportion of people having higher educational level in these three regions was lower than that in the central and eastern regions.In particular, the proportion of populations having higher educational level accounted for only $6.8,8.9$, and $11.6 \%$ in the north-eastern, northern, and southern regions, respectively. This finding was also supported by previous study in Brazil revealing that human leptospirosis was inversely associated with educational level (Dias et al. 2007) because the education influences the attitudes and concerns on preventing leptospirosis. Therefore, promoting higher educational programs might enhance the successful prevention of leptospirosis (Nozmi et al. 2018). However, at extremely heavy rainfall (i.e., 99th percentile of monthly cumulative rainfall), the locationshaving higher proportion of population with high educational level, as well as those with higher DTR, latitude, population number, and proportion of population with registered agricultural workers, showed a higher risk of leptospirosis associated with exposure to rainfall (Fig. 5). The underlying mechanismsrelated to these findings remain unclear, which require further investigation. However, it might speculate, to some extent, that the risk of leptospirosis is likely to increase during extremely heavy rainfallor flood eventswithout theinfluence of other external factorsbecausepathogenic Leptospira could disseminate well among rodent populations during heavy rainfall, especially in the areas without proper drainage systems, in which the transmission of human leptospirosis at the time is somewhat increased (Kupek et al. 2000; Smith et al. 2013).

Several limitations should be acknowledged in this study. First, the results observed in the central and eastern regions were uncertain because they represented a smaller sample size of human leptospirosis during the study period compared with that in other regions. Moreover, the human leptospirosis cases was obtained from the 506 surveillance systems that mainly used for disease control and prevention, where the number of cases might have been underreported. This occurred because the leptospirosis symptomsaresomewhat similar tothose of other febrile illnesses, leading to difficulties in distinguishing them and might not have been diagnosed as leptospirosis in some cases(Lau et al. 2010; Levett 2001). However, these underreported cases might not havemuch influenced the association observed in this 
study due to their similar infection pathways(Matsushita et al. 2018). Second, rainfall intensity was not taken into account, where only monthly total rainfall was used as the exposure proxy in this study that could haveintroduced misclassification error and biased the effect estimate toward the null. Moreover, only 60 of 77 provinces were included due to unavailable meteorological data in some provinces. Therefore, the spatial geostatistical approaches need to be considered to estimate the level of specific meteorological parameters in unmonitored areas in the future study. Third, the population immunity might have been an important factor affecting the infection and manifestation of human leptospirosis (Imai et al. 2015), but was not considered in this study. Fourth, the data used for the analysis in this study was in monthly scale, rather than weekly, where a shorter time lag effect than month could not be examined. Nevertheless, a previous study has confirmed that the weekly time lag effect showed the consistent results compared with monthly time lag effect (Suwanpakdee et al. 2015). Last, the population of hosts (e.g., rodents, buffaloes) is an important factor that is likely to confound the association between rainfall and human leptospirosis, but it was not considered in this study because the information on the number of reservoir hosts was unavailable.

Although several limitations are acknowledged, findings from this study are able to improve the understanding of leptospirosis that is likely to be associated with environmental factors. Findings could then be used to predict the leptospirosis outbreaks under specific conditions of rainfall toward climate change situation in Thailand, and contribute to designing appropriate prevention and control measuresto reduce the risk of human leptospirosis.

\section{Conclusions}

The evidence from this study revealed that higher rainfall was associated with increasing risk of human leptospirosis in Thailand. The heterogeneity of the rainfall-leptospirosis relationship among provinces and regions was also observed. In addition, the proportion of population registering as agricultural workers was an independent factor explaining the difference of the rainfall-leptospirosis association among the regions. Although without statistical significance, the northern and north-eastern regions were identified as presenting the highest risk of leptospirosis associated with rainfall because they indicated a higher proportion of population registering as agricultural workers compared with other regions. These results may help to inform policy-decision makers based at provincial, regional and even national levels to reduce the risk of human leptospirosis associated with rainfall. In addition, results of this study could be expanded in terms of projecting human leptospirosis cases associated with rainfall under different climate change scenarios in the future studies.

\section{Declarations}

\section{Acknowledgements}

The author expresses sincere gratitude to the Thai Meteorological Department and the Bureau of Epidemiology under the Ministry of Public Health of Thailand for sharing themeteorologicaland human 
leptospirosis data, respectively. The National Statistical Office (NSO) and the Department of Agriculture Extension are also acknowledged for providing useful province-specific demographical characteristic data (i.e., total number of population, the proportion of population with high educational level, the proportion of population working as agricultural workers) for the analyses in this study. The author also thanks Mr. Thomas McManamon for the professional English proofreading.

\section{Author contribution}

Conceptualization: Phosri, A.; Methodology: Phosri, A.; Formal analysis and investigation: Phosri, A.; Writing - original draft preparation: Phosri, A.; Funding acquisition: Phosri, A.; Resources: Phosri, A.

\section{Funding}

This research project is supported by Mahidol University (No. A2/2563). The funder had no role in the study design, data collection and analysis, as well as preparation of the manuscript for submission.

\section{Data availability}

The data that support findings of this study areavailable from the corresponding author on reasonable request.

\section{Ethicsapproval}

This study was approved by the Ethics Review Committee (ERC) for human research of the Faculty of Public Health, Mahidol University (No.164/2563) as exemption review. Written informed consent was not required because anonymous aggregated secondary data were applied in this study.

\section{Consent to participate:}

Not applicable

\section{Consent for publication:}

Not applicable

\section{Conflict of interest}

The author has no competing interests to declare that are relevant to the content of this article

\section{References}

1. Altheimer K, Jongwattanapisan P, Luengyosluechakul S, Pusoonthornthum R, Prapasarakul N, Kurilung Aet al (2020) Leptospira infection and shedding in dogs in Thailand. BMC Vet Res 16:1-13. https://doi.org/10.1186/s12917-020-2230-0 
2. Bharti AR, Nally JE, Ricaldi JN, Matthias MA, Diaz MM, Lovett MAet al(2003) Leptospirosis: A zoonotic disease of global importance. Lancet Infect Dis3:757-771.https://doi.org/10.1016/S14733099(03)00830-2

3. Bureau of Epidemiology(2019)Case definition for surveillance [in

Thai].http://www.boe.moph.go.th/boedb/surdata/disease.php?dcontent=def\&ds=43 [accessed 30 October 2020]

4. Chadsuthi S, Bicout DJ, Wiratsudakul A, Suwancharoen D, Petkanchanapong W, Modchang C et al (2017) Investigation on predominant Leptospira serovars and its distribution in humans and livestock in Thailand, 2010-2015. PLoS Negl Trop Dis 11:20102015.https://doi.org/10.1371/journal.pntd.0005228

5. Chadsuthi S, Modchang C, Lenbury Y, lamsirithaworn S, Triampo W (2012) Modeling seasonal leptospirosis transmission and its association with rainfall and temperature in Thailand using timeseries and ARIMAX analyses. Asian Pac J Trop Med 5:539-546.https://doi.org/10.1016/S19957645(12)60095-9

6. Costa F, Hagan JE, Calcagno J, Kane M, Torgerson P, Martinez-silveira MSet al (2015) Global morbidity and mortality of leptospirosis: A systematic review. PLoS Negl Trop Dis 9:e0003898.https://doi.org/10.1371/journal.pntd.0003898

7. Desvars A, Jégo S, Chiroleu F, Bourhy P, Cardinale E, Michault A (2011) Seasonality of human leptospirosis in Reunion Island (Indian Ocean) and its association with meteorological data. PLoS One 6:e20377. https://doi.org/10.1371/journal.pone.0020377

8. Dhewantara PW, Hu W, Zhang W, Yin WW, Ding F, Al Mamun Aet al(2019) Climate variability, satellitederived physical environmental data and human leptospirosis: A retrospective ecological study in China. Environ Res 176:108523. https://doi.org/10.1016/j.envres.2019.06.004

9. Dias JP, Teixeira MG, Costa MCN, Mendes CMC, Guimarães P, Reis MGet al(2007) Factors associated with Leptospira sp infection in a large urban center in northeastern Brazil. Rev Soc Bras Med Trop 40:499-504. https://doi.org/10.1590/S0037-86822007000500002

10. Gasparrini A(2011) Distributed lag linear and non-linear models in R: the package dlnm. J Stat Softw43:1-20.

11. Gasparrini A, Armstrong B, Kenward MG (2010) Distributed lag non-linear models. Stat Med 29:2224-2234. https://doi.org/10.1002/sim.3940

12. Gasparrini A, Armstrong B, Kenward MG (2012) Multivariate meta-analysis for non-linear and other multi-parameter associations. Stat Med 31:3821-3839. https://doi.org/10.1002/sim.5471

13. Gonwong S, Chuenchitra T, Khantapura P, Islam D, Ruamsap N, Swierczewski BEet al (2017) Nationwide seroprevalence of leptospirosis among young Thai men, 2007-2008. Am J Trop MedHyg 97:1682-1685. https://doi.org/10.4269/ajtmh.17-0163

14. Haake DA, Levett PN (2015) Leptospirosis in humans. In:Leptospira and Leptospirosis. Adler B, ed. Heidelberg, Berlin: Springer. https://doi.org/10.1007/978-3-662-45059-8_5 
15. Hacker KP, Sacramento GA, CruzJS, De Oliveira D, Nery N, Lindow JCet al (2020) Influence of rainfall on Leptospira infection and disease in a tropical urban setting, Brazil. Emerg Infect Dis26:311-314. https://doi.org/10.3201/eid2602.190102

16. Herrmann-Storck C, Brioudes A, Quirin R, Deloumeaux J, Lamaury I, Nicolas Met al(2005)

Retrospective review of leptospirosis in Guadeloupe, French West Indies 1994-2001. West Indian Med J 54:42-46. https://doi.org/10.1590/S0043-31442005000100009

17. Imai C, Armstrong B, Chalabi Z, Mangtani P, Hashizume M (2015) Time series regression model for infectious disease and weather. Environ Res 142:319-327.

https://doi.org/10.1016/j.envres.2015.06.040

18. Kupek E, de Sousa Santos Faversani MC, de Souza Philippi JM (2000) The relationship between rainfall and human leptospirosis in Florianópolis, Brazil, 1991-1996. Braz J Infect Dis 4:131-134.

19. Lau CL, Smythe LD, Craig SB, Weinstein P (2010) Climate change, flooding, urbanisation and leptospirosis: Fuelling the fire? Trans R Soc Trop Med Hyg 104:631-638.

https://doi.org/10.1016/j.trstmh.2010.07.002

20. Levett PN(2001) Leptospirosis. Clin Microbiol Rev 14:296-326.

https://doi.org/10.1128/CMR.14.2.296-326.2001

21. Matsushita N, Ng CFS, Kim Y, Suzuki M, Saito N, Ariyoshi Ket al(2018) The non-linear and lagged short-term relationship between rainfall and leptospirosis and the intermediate role of floods in the Philippines. PLoS Negl Trop Dis12:e0006331. https://doi.org/10.1371/journal.pntd.0006331

22. Mohan ARM, Cumberbatch A, Adesiyun AA, Chadee DD (2009) Epidemiology of human leptospirosis in Trinidad and Tobago, 1996-2007: A retrospective study. Acta Trop 112:260-265.

https://doi.org/10.1016/j.actatropica.2009.08.007

23. Mwachui MA, Crump L, Hartskeerl R, Zinsstag J, Hattendorf J (2015) Environmental and behavioural determinants of leptospirosis transmission: A systematic review. PLoS NeglTrop Dis9:1-15. https://doi.org/10.1371/journal.pntd.0003843

24. Nozmi N, Samsudin S, Sukeri S, Shafei MN, Wan Mohd WMZ, Idris Zet al(2018) Low levels of knowledge, attitudes and preventive practices on leptospirosis among a rural community in Hulu Langat District, Selangor, Malaysia. Int J Environ ResPublic Health 15:693.

https://doi.org/10.3390/ijerph15040693

25. Pappas G, Papadimitriou P, Siozopoulou V, Christou L, Akritidis N(2008) The globalization of leptospirosis: worldwide incidence trends. Int J Infect Dis 12:351-357. https://doi.org/10.1016/j.ijid.2007.09.011

26. Pawar S, Kore M, Athalye A, Thombre P(2018) Seasonality of leptospirosis and its association with rainfall and humidity in Ratnagiri, Maharashtra. Int J Health Allied Sciences 7:37-40. https://doi.org/10.4103/ijhas.IJHAS_35_16

27. Perez J, Brescia F, Becam J, Mauron C, Goarant C (2011) Rodent abundance dynamics and Leptospirosis carriage in an area of hyper-endemicity in new Caledonia. PLoS Negl Trop Dis 5(10):e1361. https://doi.org/10.1371/journal.pntd.0001361

Page 15/21 
28. Premdas AK, Areekal B, Sukumaran ST, Raj Kunnumel Kandi A (2019) Trend of leptospirosis and its association with meteorological factors in Thrissur district, Kerala. Int J Community Med Public Health 6:4857. https://doi.org/10.18203/2394-6040.ijcmph20195068

29. $R$ Development Core Team (2019)A language and environment for statistical computing. $R$ Foundation for Statistical Computing. Vienna, Austria. https://www.r-project.org/

30. Ridzlan FR, Bahaman AR, Khairani-Bejo S, Mutalib AR (2010) Detection of pathogenic Leptospirafrom selected environment in Kelantan and Terengganu, Malaysia. Trop Biomed 27:632638.

31. Robertson C, Nelson TA, Stephen C(2012) Spatial epidemiology of suspected clinical leptospirosis in Sri Lanka. Epidemiol Infect 140:741-743. https://doi.org/10.1017/S0950268811001014

32. Smith JKG, Young MM, Wilson KL, Craig SB (2013) Leptospirosis following a major flood in Central Queensland, Australia. Epidemiollnfect 141:585-590. https://doi.org/10.1017/S0950268812001021

33. Suwanpakdee S, Kaewkungwal J, White LJ, Asensio N, Ratanakorn P, Singhasivanon P et al(2015) Spatio-temporal patterns of leptospirosis in Thailand: is flooding a risk factor? Epidemiollnfect, 143:2106-2115. https://doi.org/10.1017/s0950268815000205

34. Tangkanakul W, Tharmaphornpil P, Plikaytis BD, Bragg S, Poonsuksombat D, Choomkasien Pet al (2000) Risk factors associated with leptospirosis in Northeastern Thailand, 1998. Am J Trop MedHyg 63:204-208. https://doi.org/10.4269/ajtmh.2000.63.204

35. Victoriano AFB, Smythe LD, Gloriani-Barzaga N, Cavinta LL, Kasai T, Limpakarnjanarat K et al(2009) Leptospirosis in the Asia Pacific region. BMC Infect Dis 9:147.https://doi.org/10.1186/1471-2334-9147

36. Watt G, Jongsakul K, Suttinont C (2003) Possible scrub typhus coinfections in Thai agricultural workers hospitalized with leptospirosis. Am J Trop Med Hyg68:89-91.

https://doi.org/10.4269/ajtmh.2003.68.89

\section{Tables}

Table 1 Descriptive statistics for monthly number of human leptospirosis, monthly cumulative rainfall, average temperature and relative humidity during the study period $(2007-2017)$ in 60 provinces

\begin{tabular}{|lllllll|}
\hline Variables & Mean & Min & P25 & P50 & P75 & Max \\
\hline Monthly leptospirosis counts & 4.9 & 0.0 & 0.0 & 1.0 & 5.0 & 264.0 \\
\hline Rainfall $(\mathrm{cm})$ & 15.3 & 0.0 & 2.6 & 11.3 & 21.8 & 186.3 \\
\hline Temperature $\left({ }^{\circ} \mathrm{C}\right)$ & 27.3 & 17.7 & 26.5 & 27.6 & 28.5 & 34.4 \\
\hline Humidity $(\%)$ & 76.5 & 43.4 & 71.5 & 78.3 & 82.3 & 92.2 \\
\hline
\end{tabular}


Note: Descriptive statistics are reported, where Min and Max denote minimum and maximum value, respectively. P25, P50, and P75 refer to 25th percentile (1st quartile), 50th percentile (median), and 75th percentile (3rd quartile), respectively.

Table 2 Summary statistics for region-specific characteristics

\begin{tabular}{|llllll|}
\hline Regions & $\begin{array}{l}\text { Latitude } \\
\left({ }^{\circ} \mathrm{N}\right)\end{array}$ & DTR $\left({ }^{\circ} \mathrm{C}\right)$ & $\begin{array}{l}\text { Population } \\
\left(\times 10^{5}\right)\end{array}$ & $\begin{array}{l}\text { High education } \\
(\%)\end{array}$ & $\begin{array}{l}\text { Agriculturists } \\
(\%)\end{array}$ \\
\hline $\begin{array}{l}60 \\
\text { provinces }\end{array}$ & $14.09 \pm 3.86$ & $9.76 \pm 1.25$ & $9.15 \pm 7.92$ & $10.09 \pm 6.44$ & $10.71 \pm 3.61$ \\
\hline Northern & $17.86 \pm 1.20$ & $10.86 \pm 0.98$ & $7.16 \pm 3.70$ & $8.93 \pm 3.06$ & $11.72 \pm 2.27$ \\
\hline $\begin{array}{l}\text { North- } \\
\text { eastern }\end{array}$ & $16.31 \pm 1.01$ & $10.30 \pm 0.48$ & $12.03 \pm 5.85$ & $6.75 \pm 2.13$ & $12.87 \pm 2.01$ \\
\hline Central & $14.30 \pm 0.88$ & $9.64 \pm 1.26$ & $13.52 \pm 17.67$ & $14.71 \pm 13.57$ & $6.78 \pm 3.27$ \\
\hline Eastern & $13.21 \pm 0.70$ & $8.70 \pm 1.31$ & $6.45 \pm 3.62$ & $12.25 \pm 5.85$ & $7.06 \pm 2.89$ \\
\hline Southern & $7.95 \pm 1.26$ & $8.62 \pm 0.72$ & $6.52 \pm 4.09$ & $11.59 \pm 4.90$ & $11.15 \pm 3.93$ \\
\hline
\end{tabular}

Note: The value is indicated as mean $( \pm S D)$ for each variable. DTR, diurnal temperature range indicating monthly average DTR during the study period (i.e., 2007 - 2017); the number of population (in 2013) is shown as per $10^{5}$ populations; high education indicates the proportion of populations who have receivedbachelor's degree or above (using the information from the population and housing census version 2010); agriculturists illustrate the proportion of populations who have registered as agricultural workers (using the information of 2013).

\section{Figures}



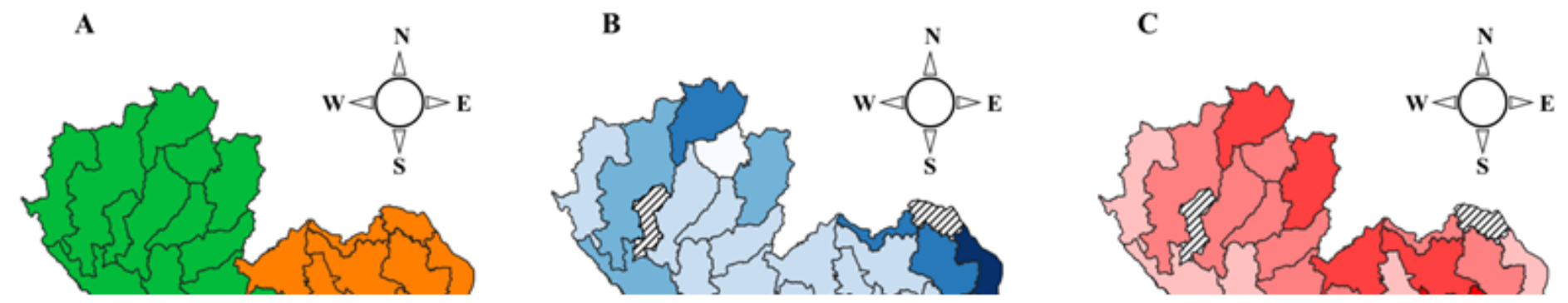

\section{Figure 1}

Geographical regions of Thailand (A), as well as the average of monthly cumulative rainfall (B) and the total number of human leptospirosis (C) for each province during the period of 2007-2017, excepting for those for a province of Nong Bua Lam Phu where the data was used during the period of 2014-2017 


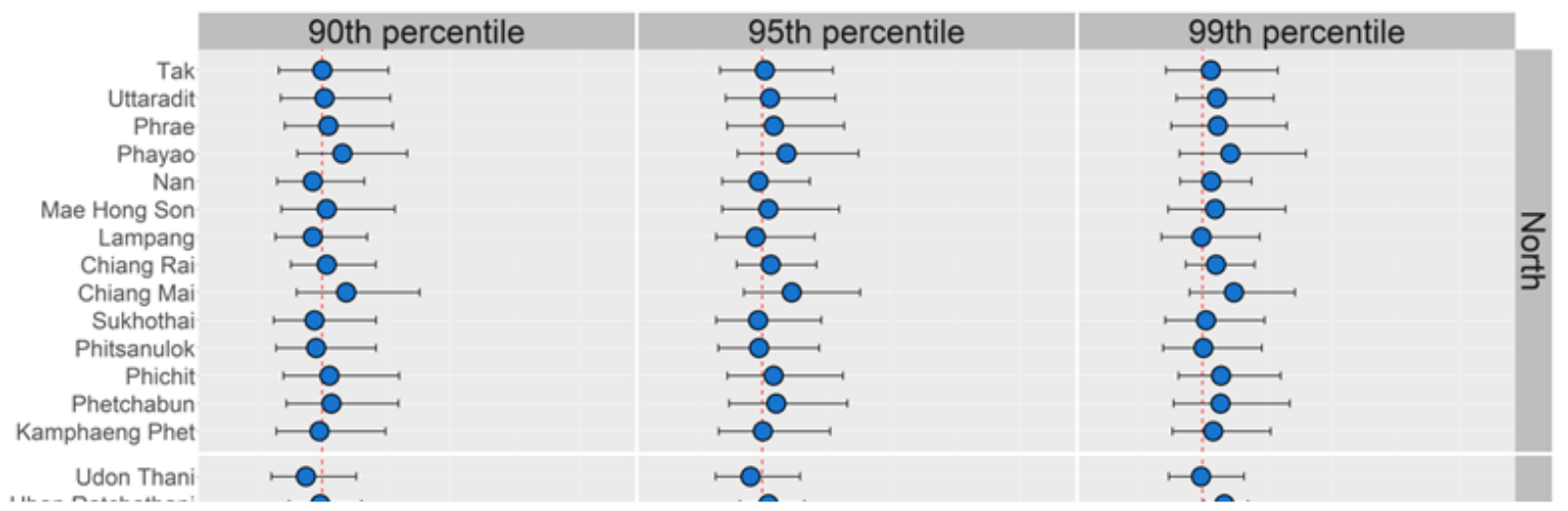

\section{Figure 2}

Province-specific effects of rainfall on leptospirosis, estimating through BLUP approach, at lag 0 month. The RR and its $95 \% \mathrm{Cl}$ of leptospirosis associated with exposure to rainfall at 90th, 95th, and 99th percentiles of province-specific monthly cumulative rainfall relative to $0 \mathrm{~cm}$ is shown. The word "All" indicate the pooled RR obtained from multivariate meta-analysis 


\section{Figure 3}

The national and region-specific rainfall-leptospirosis associations at different lag structures, estimated through multivariate meta-regression model. Grey solid line indicates rainfall level at $0 \mathrm{~cm}$, whereas black, blue, and red dotted lines indicate monthly cumulative rainfall level at 90th, 95th, and 99th percentile, respectively, for each region. $P$ and $p$-value of $Q$ test is the measure of the residual heterogeneity of the association between rainfall and leptospirosis at lag 0 month for each region obtained via multivariate meta-regression model

(a) 60 provinces of Thailand

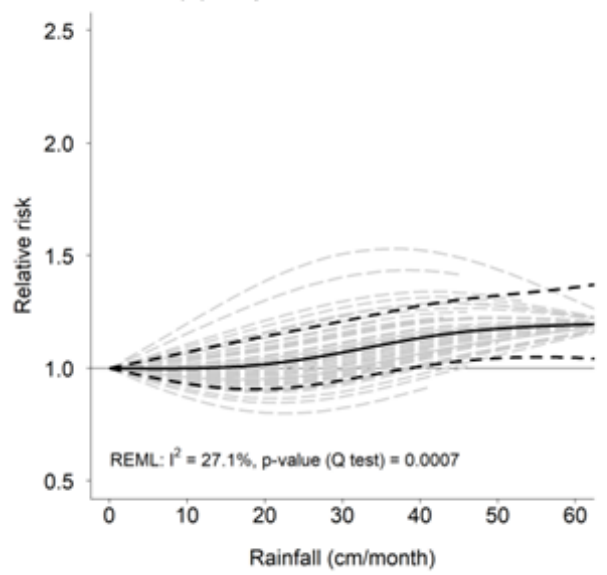

(d) Northeastern (17 provinces)

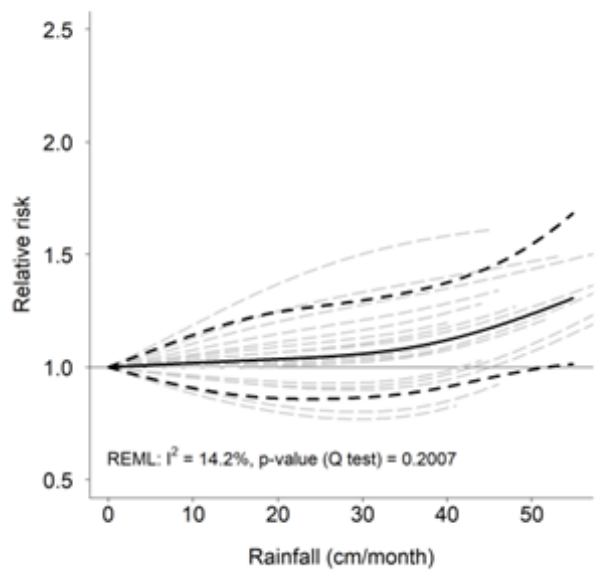

(b) Central (8 provinces)

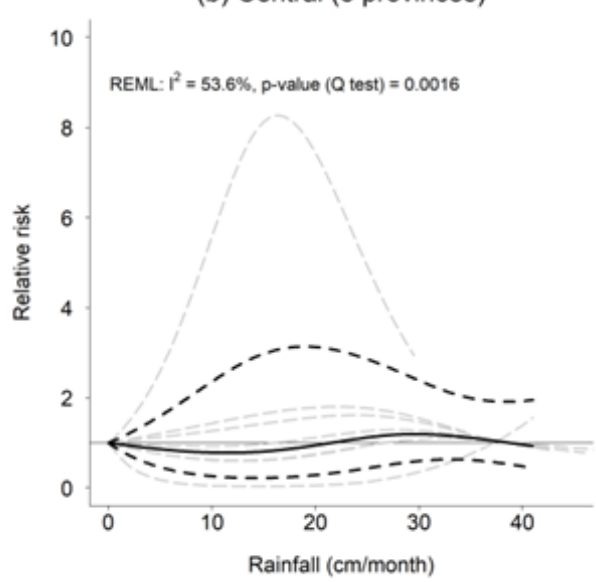

(e) Eastern (7 provinces)

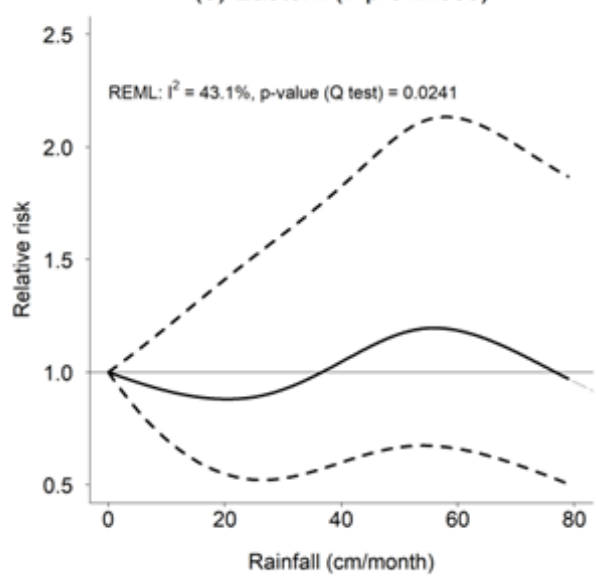

(c) Northern (14 provinces)

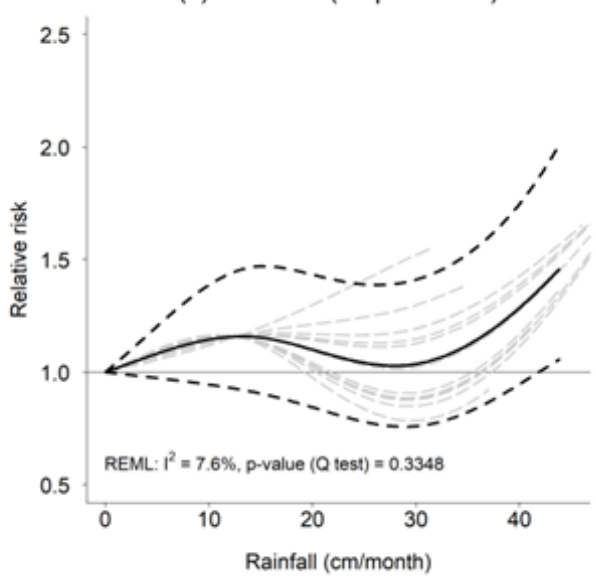

(f) Southern (14 provinces)

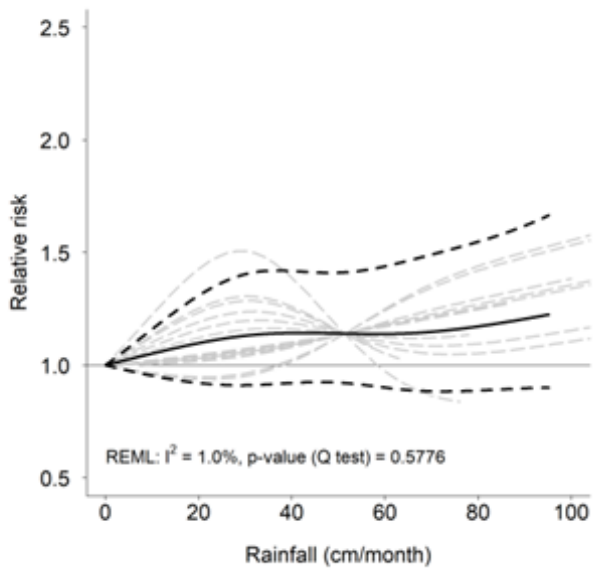

\section{Figure 4}

The pooled national and region-specific rainfall-leptospirosis association at lag 0 month, estimated through multivariate meta-regression model. Black solid line indicates pooled RR with its $95 \%$ confidence interval shown as black dashed lines. Grey dashed lines define province-specific RR incorporated in metaanalysis through BLUP method. $I^{2}$ and $p$-value of $Q$ test indicate the measure of the residual heterogeneity obtained from multivariate meta-regression model 
(a) No meta-regressor

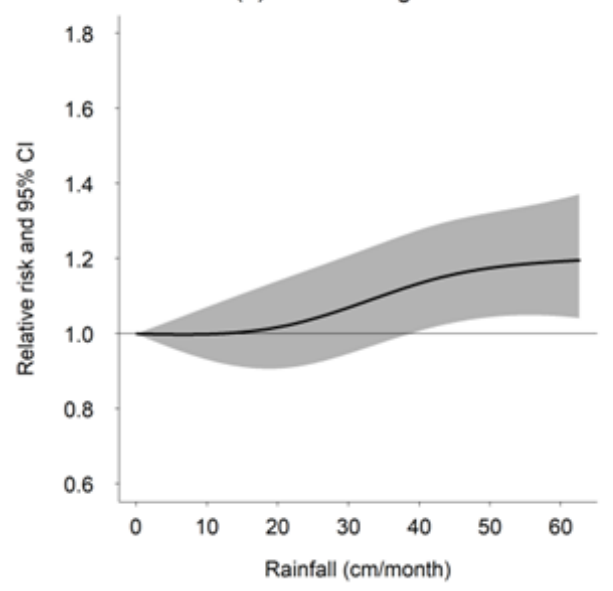

(d) Population $(x 100,000)$

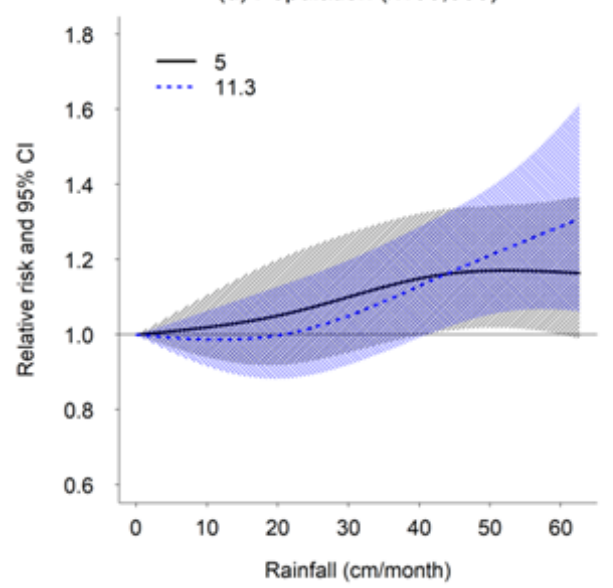

(b) Diurnal temperature range $\left({ }^{\circ} \mathrm{C}\right)$

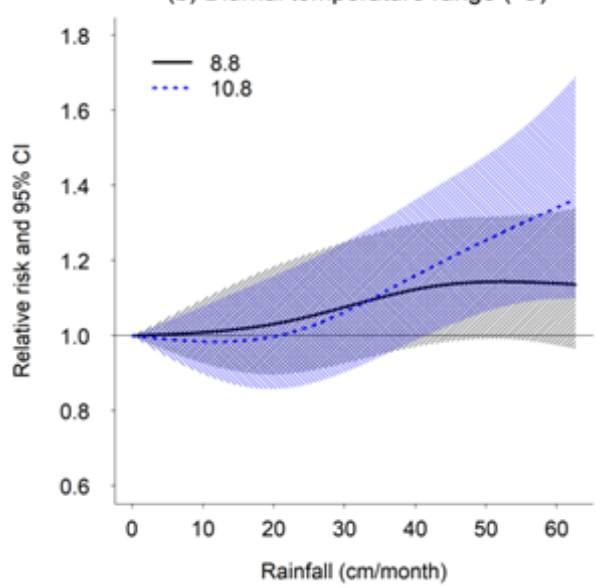

(e) High education (\%)

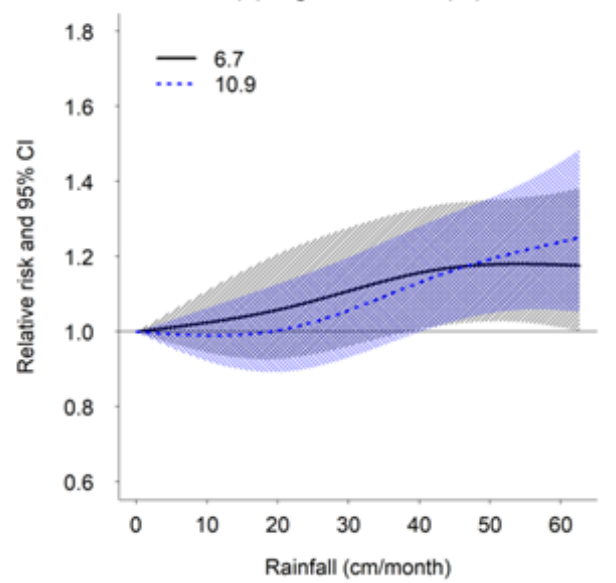

(c) Latitude $\left({ }^{\circ} \mathrm{N}\right)$

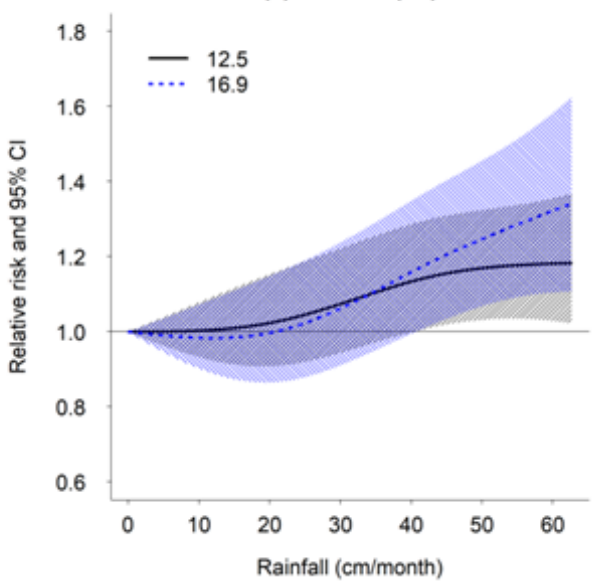

(f) Populations who work as agriculturist (\%)

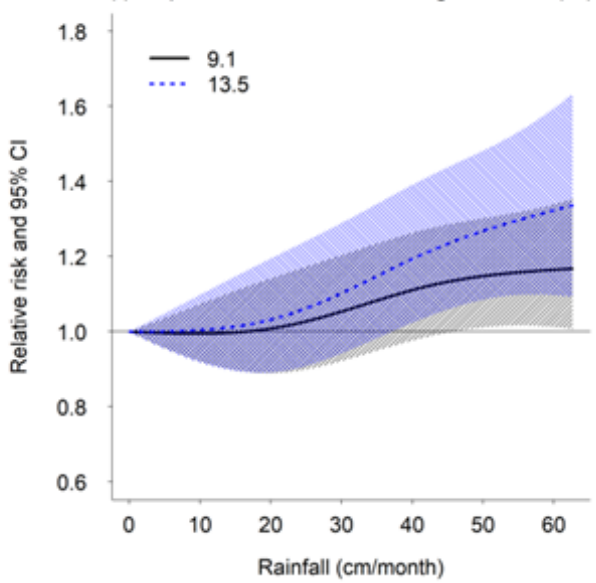

Figure 5

The national rainfall-leptospirosis association (lag 0 month) at specific level of geographical and population characteristics, predicted through multivariate meta-regression model. The figure shows predicted curve of the association between rainfall and leptospirosis with no predictor (a) and at 25th (black solid line) and 75th (blue dashed line) percentiles of DTR (b), latitude (c), number of population (d), proportion of population with higher education (e), and proportion of population with registered agricultural workers (f). The shaded areas define the corresponding $95 \%$ confidence intervals

\section{Supplementary Files}

This is a list of supplementary files associated with this preprint. Click to download.

- Supplementarymaterials.docx 